\title{
DIVERTICULOSIS OF THE JEJUNUM AS A CAUSE OF INTESTINAL OBSTRUCTION
}

\author{
M. Javed Rajput, Abdul Sattar Memon and Shabnum Rani
}

\begin{abstract}
Jejunal diverticuli are rare, usually asymptomatic, and seen as incidental findings. Complications such as bleeding, perforation, diverticulitis and intestinal obstruction may warrant surgical intervention. This is case report of an old man who presented with sub acute intestinal obstruction. Exploratory laparotomy revealed jejunal diverticuli adherent to previous epigastric hernia repair scar along with omentum causing intestinal obstruction. Resection and end-to-end anastomosis was done.
\end{abstract}

KEY WORDS: Jejunal diverticulum. Sub acute intestinal obstruction. Resection. End-to-end anastomosis.

\section{INTRODUCTION}

Jejunal diverticulum is an uncommon acquired condition, and majority of the patients is usually asympatomatic. A diagnosis of small intestinal diverticulosis is difficult to make preoperatively because the clinical symptoms are usually non-specific. But jeujunal diverticulum should not always be dismissed as asymptomatic findings, as they may be the cause of vague, chronic symptomatology and acute complication including intestinal obstruction, haemorrhage and perforation. Awareness of the fact that jejunal diverticula may cause chronic non specific abdominal symptoms and serious acute complication may lead to earlier diagnosis and timely treatment. We report the case of an old man with jejunal diverticulum who developed sub-acute intestinal obstruction two months after the repair of an epigastric hernia.

\section{CASE REPORT}

A 70 years old male admitted in surgical ward with pain and distension of abdomen for 2-days had not passed stool for 5-days. He was afebrile with nausea and pulse rate $92 / \mathrm{min}$, BP 110/70 $\mathrm{mmHg}$. On abdominal examination, there was an upper-midline scar of epigastric hernia with fullness of upper abdomen. On palpation, patient had mild tenderness in upper abdomen with no visceromegaly having exaggerated bowel sounds. X-ray abdomen in erect and supine postures were non conclusive. Patient was put on conservative therapy with diagnosis of sub acute adhesive obstruction due to previous surgery. In next two days, he did well. He passed stool, distension of abdomen decreased and was allowed clear fluids orally. But next day, he again developed complete obstruction with distension of abdomen and vomiting. At that time, a laparotomy was planned. On exploration, omentum along with a loop of jejunum having two diverticuli, two inches a part were found adherent to previous scar. Jejunum proximal to that was distended and distil jejunum, ileum and colon were collapsed. A band traversing mid small intestine was also found, which was extending upto the base of $2^{\text {nd }}$ diverticulum. The first diverticulum also had chyme inside, and both had free communication with the lumen of jejunum (Figure I). The band was removed and the segment of jejunum having diverticuli was separated from the scar. Resection and end-to-end anastomosis were done with absorbable suture in single layer. Postoperative course was uneventful.

FIGURE I:

RESECTED SEGMENT OF JEJUNUM HAVING TWO DIVERTICULI ALONG WITH CHYME

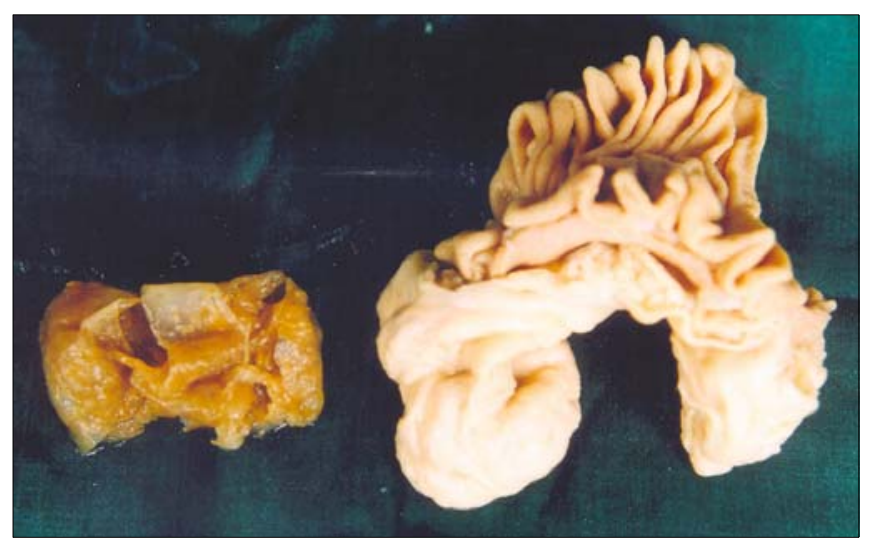

\section{DISCUSSION}

Jejunal diverticulum is an uncommon, acquired condition, and the majority of patients is usually asymptomatic. Its preoperative diagnosis is difficult to make as the clinical symptoms are usually non-specific ${ }^{1}$. Jejunal diverticulum becomes clinically relevant when complications develop ${ }^{2}$. Documented complications related to jejunal diverticulum are diverticulitis, intesti- 
nal bleeding, obstruction or perforation ${ }^{3}$. These occur twice as frequently in men. In recent past, age group in all reported cases is above 70-years ${ }^{4}$. Intestinal obstruction, when present, is either because of an associated band or enterolithiasis. Among above said complications, patients with multiple jejunal diverticular complications by jejuno-coli fistula is also documented in literature ${ }^{5}$. Although often incidentally found in the radiographic examination of the small intestine, contrast study of the small intestine by enteroclysis is suggested as the method of choice by some to determine jejunal diverticula whereas some patients have also presented with massive intestinal haemorrhage from jejunal diverticlui ${ }^{6,7}$. For obscure bleeding technecium $^{8,9}$ scan with autologus RBCs may be helpful. The diagnosis in initial stage, specially if having some faecolith inside can be suggested by ultrasound which detects a hypoechoic irregular lesion continuous with the jejunum, that can be further confirmed by CT scan, which in case of diverticulitis picks it up as inflamed diverticulum, inflammatory mesenteric infiltration, extraluminal gas collection and mural oedema of adjacent small bowel loops resulting into separation of bowel loops ${ }^{8,9}$. Small bowel obstruction due to enterolithiasis expelled from jejunal diverticulum is a rare condition. The least invasive step suggested in the therapeutic approach is to crush and milk the obstructing enterolith down to the colon. Laparoscopic crushing and milking of the enterolith is described. If this fails, an enterostomy could be tried. If the first two strategies fail, or if any complication is present, resection of the involved jejunal segment with end-to-end anastomosis could be considered ${ }^{10}$.

\section{REFERENCES}

1. Costa G, Moncini R, DiCastro A, Capaldi M,
Sciacc P, lahongo P. Perforated jejunal diverticulum: a rare cause of acute abdomen. Chir Ital. 2005; 57 (4): 521-5. [Article in Italian]

2. Lin $\mathrm{CH}$, Hsieh HF, Yu CY, Yu JC, Chan DC, Chen TW, et al. Diverticulosis of the jejunum with intestinal obstruction: A case report. World J Gastroenterol. 2005; 11(34): 5416-7.

3. Subrt Z, Paral J, Kaska M. Jejunal diverticulosis as a rare cause of massive bleeding into digestive tract - case report. Rozhl Chir, 2004; 83 (10): 514-7.[Czech)

4. Kornprat $P$, Langner $\mathrm{C}$, Mischinger HJ. Enterolithiasis in jejunal deverticulosis, a rare cause of obstruction of the small intestine: A case report. Wien Klin Wochenschr. 2005; 117(7-8): 297-9.

5. Lempinen $M$, Salmela K, Kemppainen E. Jejunal diverticulosis: a potentially dangerous entity. Scand J Gastroenterol. 2004; 39(9): 905-9.

6. Surov A, Stock K. Jejunal diverticulosis. Eur J Med Res. 2005; 10 (8): 358-60.

7. Franke C, Grust A, Frieling T, Simon D. Jejunum diverticulosis: a rare case of gastrointestinal hemorrhage. Zentralbl Chir. 2001;126(9):707-9. [German]

8. Kelekis AD, Poletti PA. Jejunal diverticulitis with localized perforation diagnosed by ultrasound - a case report. Eur Radiol. 2004;14(3):541.

9. Ferstl GJ, Obert R. CT findings in acute small bowel diverticulitis. Rofo. 2004; 176(2): 246-51. [Article in German]

10. Steenvoorde $P$, Schaardenburgh $P$, Viersma JH. Enterolith ileus as a complication of jejunal deverticulosis: two case reports and a review of the literature. Dig Surg. 2003; 20(1): $57-60$.

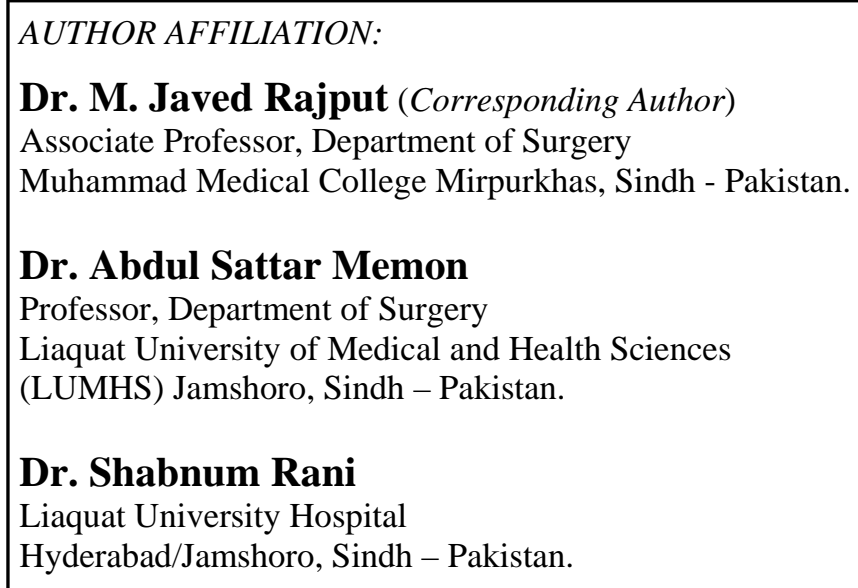

